\title{
A constitutive model for analysis of reinforced concrete solids
}

\author{
R.G. Selby and F.J. Vecchio
}

\begin{abstract}
This paper describes formulations intended to expand the applicability of the modified compression field theory for general three-dimensional analysis of reinforced concrete solids. The modified compression field theory, which was specifically developed from tests on cracked reinforced concrete panels, has primarily concentrated on describing the stress-strain response of reinforced concrete under compression and tension stress states. Recent work has been directed at refining finite element programs based on the modified compression field theory for problems in which confinement and lateral expansion effects are important. Proposed stress-strain relationships are based on an orthotropic nonlinear elastic model that acknowledges the asymmetric response of concrete under multiaxial stress conditions. Lateral expansion of concrete subjected to compression is modelled under all stress states. The formulation accounts for complex behaviour such as concrete strength enhancement due to confinement, concrete strength degradation due to transverse cracking, tension stiffening, and crack slip. The models assume short-term, monotonic loading conditions. A sample analysis of a reinforced concrete shear wall is presented to illustrate the improved modelling with the consideration of lateral expansion and confinement effects.
\end{abstract}

Key words: reinforced concrete, triaxial stress, confinement, lateral expansion, orthotropic, cracking.

Résumé : Cet articles décrit des formulations proposées pour élargir le domaine d'application de la théorie du domaine de compression modifiée pour le cas général d'analyse tridimensionnelle d'éléments en béton armé. La théorie du domaine de compression modifiée, qui a été spécifiquement développée à partir d'essais sur des panneaux fissurés en béton armé, s'est essentiellement concentrée sur la description de la relation contrainte-déformation du béton armé sous des contraintes de compression-traction. De récents travaux ont été entrepris pour raffiner des programmes d'éléments finis basés sur la théorie du domaine de compression modifiée afin de considérer des problèmes dans lesquels le confinement et l'expansion latérale sont importants. Les relations proposées de contrainte-déformation sont basées sur un modèle orthotropique élastique et non-linéaire qui reconna"t la réponse asymétrique du béton sous l'effet de contraintes multiaxiales. La formulation tient compte de comportements complexes tels que l'amélioration de la résistance du béton due au confinement, la dégradation de la résistance du béton à cause de fissurations transversales, le raidissement en tension et le glissement de fissures. L'analyse d'un mûr de cisaillement en béton armé est présenté pour illustrer la modélisation améliorée en considérant l'expansion latérale et les effets de confinement.

Mots clés : béton armé, contrainte triaxiale, confinement, expansion latérale, orthotropique, fissuration. [Traduit par la Rédaction]

\section{Introduction}

In an effort to determine more realistic constitutive relationships for cracked reinforced concrete, Vecchio and Collins (1982) tested a series of reinforced concrete panels. From these tests, the modified compression field theory, which included stress-strain relationships for cracked reinforced concrete under plane stress conditions, was derived. In this theory, directions of principal stress and directions of principal strain were

Received October 24, 1995.

Revised manuscript accepted December 11, 1996.

R.G. Selby. Morrison Hershfield Ltd., 4 Lansing Square, North York, ON M2J 1T1, Canada.

F.J. Vecchio. Department of Civil Engineering, University of Toronto, Toronto, ON M5S 1A4, Canada.

Written discussion of this article is welcomed and will be received by the Editor until October 31, 1997 (address inside front cover). assumed to coincide. Cracked concrete was treated as an orthotropic material with its own stress-strain relationships in terms of average stress and average strain. Of particular significance was that these relationships reflected the reduced compressive strength of concrete in the presence of large transverse tensile strains, and accounted for the significant tensile stresses that exist in the concrete between cracks. Local stress conditions at cracks were also examined. The modified compression field theory was shown to be capable of accurately predicting the response of reinforced concrete elements subjected to in-plane shear and normal stresses.

Adeghe (1986) and Stevens (1987) were the first to use the constitutive models of the modified compression field theory in finite element work. Each of these programs used a plane stress element and was cast in a tangent stiffness algorithm. Some numerical difficulties were encountered in modelling the softening branches of the concrete stress-strain curves in tension and compression. Also, the tangent stiffness matrix computed according to the modified compression field theory is unsymmetric. (The asymmetry in the tangent material stiffness 
matrix results because the stress-strain relationships of the modified compression field theory state, for example, that the compressive principal stress depends on the compressive principal strain and the tensile principal strain, but that the tensile principal stress depends only upon the tensile principal strain.) In an attempt to overcome these problems, both Adeghe and Stevens were forced to compromise the formulations of the modified compression field theory.

To avoid the problems encountered by these tangent stiffness approaches, Vecchio (1989) developed a secant stiffness algorithm for analysis of reinforced concrete subject to conditions of plane stress. By using a secant stiffness based approach, the asymmetry of the stiffness matrix was avoided while still completely representing the modified compression field theory. The program proved to be numerically robust, while predicting the strength, deformation pattern, and failure mode with good accuracy for a variety of membrane structures (Vecchio 1992, 1990, 1989).

The constitutive relationships of the modified compression field theory were first used in a three-dimensional finite element context by Vecchio and Selby (1991). The plane stress constitutive relationships were tentatively extrapolated to three dimensions. In accordance with the two-dimensional formulation of Vecchio, the program (SPARCS) used a secant stiffness algorithm with a smeared, rotating crack model. As a check on the proposed algorithm, a series of reinforced concrete beams subjected to varying conditions of flexure and torsion were modelled. The program was able to provide realistic predictions of ultimate load, failure mode, load-deformation response, and local strain conditions.

This paper discusses some of the recent research work (Selby and Vecchio 1993) that have been directed at improving these tentative three-dimensional constitutive relationships. In particular, models to include the effects of lateral expansion and confinement are formulated to be compatible with the existing cracked concrete theory. The confined concrete theory is implemented in an orthotropic nonlinear elastic model, consistent with the crack model. Simple confined concrete stress-strain relationships are developed from basic experimentally observed behaviour of concrete specimens subjected to multiaxial compressive stresses. These constitutive relationships represent a first attempt at developing triaxial theory to be used with the modified compression field theory.

A sample full-scale finite element analysis of a shear wall is also presented. The analysis examines the effects of accounting for confinement and lateral expansion in a compression field based analysis.

\section{Finite element formulation}

The finite element program SPARCS was developed (Vecchio and Selby 1991) to allow for compression field analysis of reinforced concrete solids. A relatively simple approach is taken with respect to the finite elements and the solution techniques that are employed. The program is based on an iterative total stress and strain formulation in which secant moduli are defined and progressively refined according to current local stress-strain states. The program uses relatively low powered brick, wedge, and truss elements based on linear displacement functions. The geometry of the brick and wedge elements is restricted to enable explicit evaluation of the element stiffness matrices, thus avoiding costly numerical integration schemes.

The constitutive relationships of the modified compression field theory are best implemented into secant stiffness based algorithms. In the proposed constitutive models, an orthotropic formulation is used for concrete in all stress states. Cracked concrete treated by the smeared crack approach is inherently modelled as an orthotropic material. In confined concrete, the adoption of an orthotropic model allows for the consideration of anisotropic behaviour near ultimate.

The three-dimensional orthotropic material stiffness matrix can be written in the principal directions as

$$
\left[D_{\mathrm{c}}\right]^{\prime}=\frac{1}{\phi}\left[\begin{array}{cccccc}
E_{\mathrm{c} 1}\left(1-v_{32} v_{23}\right) & E_{\mathrm{c} 1}\left(v_{12}+v_{13} v_{32}\right) & E_{\mathrm{c} 1}\left(v_{13}+v_{12} v_{23}\right) & 0 & 0 & 0 \\
E_{\mathrm{c} 2}\left(v_{21}+v_{31} v_{23}\right) & E_{c 2}\left(1-v_{31} v_{13}\right) & E_{\mathrm{c} 2}\left(v_{23}+v_{21} v_{13}\right) & 0 & 0 & 0 \\
E_{\mathrm{c} 3}\left(v_{31}+v_{21} v_{32}\right) & E_{\mathrm{c} 3}\left(v_{32}+v_{12} v_{31}\right) & E_{\mathrm{c} 3}\left(v_{23}+v_{21} v_{13}\right) & 0 & 0 & 0 \\
0 & 0 & 0 & \phi G_{\mathrm{c} 12} & 0 & 0 \\
0 & 0 & 0 & 0 & \phi G_{\mathrm{c} 23} & 0 \\
0 & 0 & 0 & 0 & 0 & \phi G_{\mathrm{c} 31}
\end{array}\right]
$$

where $E_{\mathrm{c} i}$ is the modulus of elasticity in the $i$-direction, the Poisson's ratio $v_{i j}$ is the component of strain in the $i$-direction due to a stress in the $j$-direction, and

[2] $\phi=1-v_{32} v_{23}-v_{21} v_{12}-v_{31} v_{13}-v_{21} v_{32} v_{13}-v_{31} v_{12} v_{23}$

The three shear moduli are given by

$$
G_{\mathrm{c} 12}=\frac{E_{\mathrm{c} 1} E_{\mathrm{c} 2}}{E_{\mathrm{c} 1}\left(1+\mathrm{v}_{12}\right)+E_{\mathrm{c} 2}\left(1+\mathrm{v}_{21}\right)}
$$

$$
\begin{aligned}
G_{\mathrm{c} 23} & =\frac{E_{\mathrm{c} 2} E_{\mathrm{c} 3}}{E_{\mathrm{c} 2}\left(1+\mathrm{v}_{23}\right)+E_{\mathrm{c} 3}\left(1+\mathrm{v}_{32}\right)} \\
G_{\mathrm{c} 13} & =\frac{E_{\mathrm{c} 1} E_{\mathrm{c} 3}}{E_{\mathrm{c} 1}\left(1+\mathrm{v}_{13}\right)+E_{\mathrm{c} 3}\left(1+\mathrm{v}_{31}\right)}
\end{aligned}
$$


Fig. 1. Symmetry conditions in the orthotropic model.
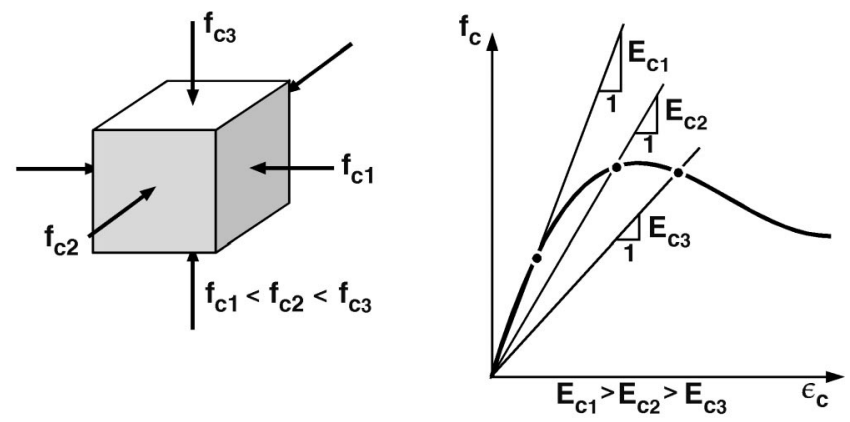

$$
\begin{aligned}
& \epsilon_{1}=\frac{f_{c 1}}{E_{c 1}}-v_{12} \frac{f_{c 2}}{E_{c 2}}-v_{13} \frac{f_{c 3}}{E_{c 3}} \\
& \epsilon_{2}=\frac{f_{c 2}}{E_{c 2}}-v_{21} \frac{f_{c 1}}{E_{c 1}}-v_{23} \frac{f_{c 3}}{E_{c 3}} \\
& \epsilon_{3}=\frac{f_{c 3}}{E_{c 3}}-v_{31} \frac{f_{c 1}}{E_{c 1}}-v_{32} \frac{f_{c 2}}{E_{c 2}}
\end{aligned}
$$

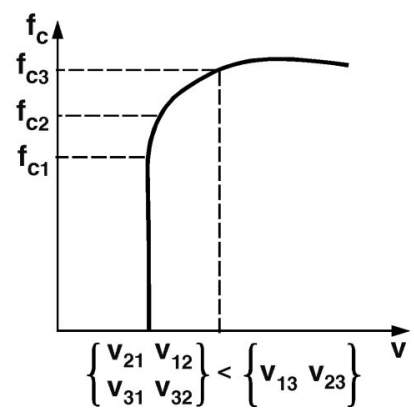

To maintain symmetry in the stiffness matrix, the following three conditions must be satisfied:

$$
\begin{aligned}
& E_{\mathrm{c} 1} \mathrm{v}_{12}=E_{\mathrm{c} 2} \mathrm{v}_{21} \\
& E_{\mathrm{c} 2} \mathrm{v}_{23}=E_{\mathrm{c} 3} \mathrm{v}_{32}
\end{aligned}
$$$$
\text { [8] } \quad E_{\mathrm{c} 1} \mathrm{v}_{13}=E_{\mathrm{c} 3} \mathrm{v}_{31}
$$

For cracked concrete, most orthotropic material descriptions (i.e., smeared crack models) have assumed that the Poisson's effects are negligible (e.g., Hu and Schnobrich 1990; Vecchio 1989). All off-diagonal terms in [1] become zero, since the six Poisson's ratios are neglected, i.e., $v_{i j}=0$. This assumption is relatively good for many situations, but for cases in which the tensile strains in cracked concrete are relatively small, the lateral expansion of concrete arising from Poisson's effects can represent a significant portion of the total strains (Vecchio 1992). Too much strength degradation, due to transverse cracking, would be predicted in this situation. Also, in triaxial compressive stress conditions the lateral expansion effects cannot be neglected.

The assumption of symmetry in the secant orthotropic model appears to contradict the observed behaviour of concrete. The constitutive response of concrete in compression is characterized by a progressively softening stress-strain curve (Fig. 1). Also, concrete exhibits a progressively higher proportion of lateral expansion as compression is increased. Considering the 2/3-plane of a specimen of triaxially compressed concrete for the case when $f_{\mathrm{c} 3}<f_{\mathrm{c} 2}$, it will generally be the case that $E_{\mathrm{c} 3}<E_{\mathrm{c} 2}$ and $v_{23}>v_{32}$. (Note that tensile values are taken positive.) Thus, in general, eq. [7] cannot be satisfied and an elastic orthotropic formulation for concrete in accordance with the symmetry conditions cannot accurately represent behaviour in which expansion effects are significant. In the proposed model, the symmetry conditions are not enforced, but an approach is used in which the asymmetry is handled through the material prestrain concept. Thus, the symmetry of the material stiffness matrices, and therefore the global stiffness matrix, is retained.

The three-dimensional finite element program SPARCS includes provisions to model prestrains arising from strain offset effects such as prestressing of reinforcement, shrinkage or expansion of concrete, and thermal expansion of either concrete or reinforcement. For concrete, a prestrain matrix, $\left\{\varepsilon_{\mathrm{c}}^{\mathrm{o}}\right\}$, is defined relative to the global $x, y, z$ system

$$
\left\{\varepsilon_{\mathrm{c}}^{\mathrm{o}}\right\}=\left\{\begin{array}{llllll}
\varepsilon_{\mathrm{c} x}^{\mathrm{o}} & \varepsilon_{\mathrm{c} y}^{\mathrm{o}} & \varepsilon_{\mathrm{c} z}^{\mathrm{o}} & \gamma_{\mathrm{c} x z}^{\mathrm{o}} & \gamma_{\mathrm{c} y z}^{\mathrm{o}} & \gamma_{\mathrm{c} z x}^{\mathrm{o}}
\end{array}\right\}^{\mathrm{T}}
$$

to account for all nonstress-related straining. A similar matrix is developed for the reinforcement prestrains. An equivalent force approach is then used to incorporate the prestrain effects. From the known prestrains, free nodal displacements $\left\{r_{\mathrm{c}}\right\}$ and $\left\{r_{\mathrm{s}}\right\}$ are calculated for the concrete and steel, respectively,

$$
\begin{aligned}
& \text { [10] }\left\{r_{\mathrm{c}}\right\}=\int\left\{\varepsilon_{\mathrm{c}}^{\mathrm{o}}\right\} \mathrm{d} V \\
& {[11] \quad\left\{r_{\mathrm{s}}\right\}=\int\left\{\varepsilon_{\mathrm{s}}^{\mathrm{o}}\right\} \mathrm{d} V}
\end{aligned}
$$

The equivalent nodal loads due to the prestrains, $\left\{F^{*}\right\}$, are calculated from

$$
\left\{F^{*}\right\}=\left[k_{\mathrm{c}}\right]\left\{r_{\mathrm{c}}\right\}+\sum_{i=1}^{n}\left[k_{\mathrm{s}}\right]_{i}\left\{r_{\mathrm{s}}\right\}_{i}
$$

where $\left[k_{\mathrm{c}}\right]$ and $\left[k_{\mathrm{s}}\right]_{i}$ are the element stiffness matrices evaluated separately for the concrete and each reinforcement component. These equivalent nodal forces due to the prestrains are then added to the externally applied nodal forces to determine the total nodal forces. The total nodal load vector is updated in each iteration, since the equivalent nodal forces depend on the component stiffnesses.

This algorithm was modified to include the expansion strains due to Poisson's effect. The expansion strains in the principal directions are written as

[13] $\left\{\varepsilon_{\mathrm{cp}}^{\mathrm{o}}\right\}=\left\{\begin{array}{lll}\varepsilon_{1}^{\mathrm{o}} & \varepsilon_{2}^{\mathrm{o}} & \varepsilon_{3}^{\mathrm{o}}\end{array}\right\}^{\mathrm{T}}$

where

$$
\begin{aligned}
& \text { [14] } \quad \varepsilon_{1}^{\mathrm{o}}=-\mathrm{v}_{12} \frac{f_{\mathrm{c} 2}}{E_{\mathrm{c} 2}}-\mathrm{v}_{13} \frac{f_{\mathrm{c} 3}}{E_{\mathrm{c} 3}} \\
& \text { [15] } \quad \varepsilon_{2}^{\mathrm{o}}=-\mathrm{v}_{21} \frac{f_{\mathrm{c} 2}}{E_{\mathrm{c} 1}}-v_{23} \frac{f_{\mathrm{c} 3}}{E_{\mathrm{c} 3}} \\
& {[16] \quad \varepsilon_{3}^{\mathrm{o}}=-\mathrm{v}_{31} \frac{f_{\mathrm{c} 1}}{E_{\mathrm{c} 1}}-\mathrm{v}_{32} \frac{f_{\mathrm{c} 2}}{E_{\mathrm{c} 2}}}
\end{aligned}
$$

The expansion strains are then transformed to the global $x, y, z$ axes according to

[17] $\left\{\varepsilon_{\mathrm{c}}^{\mathrm{o}}\right\}=[T]\left\{\varepsilon_{\mathrm{cp}}^{\mathrm{o}}\right\}$

where $[T]$ is the transformation that defines the orientation of the principal axes. Equivalent nodal loads are then calculated as outlined above. This formulation includes all straining arising from expansion in the global load vector. All of the expansion strains are modelled through the prestrain concept so the material stiffness matrix then includes diagonal terms only. 
Fig. 2. Expansion prestrains concept: $(a)$ traditional approach, $v_{12} \neq$ 0 and $(b)$ prestrain approach, $v_{12}=v_{21}=0$.

(a)

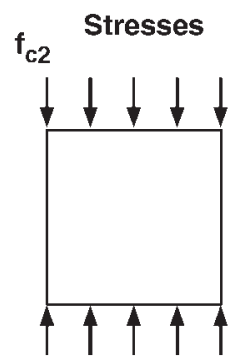

Nodal Forces

Strains
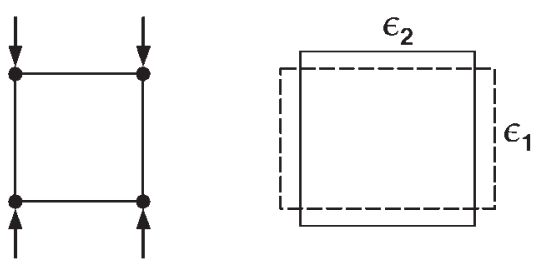

(b)

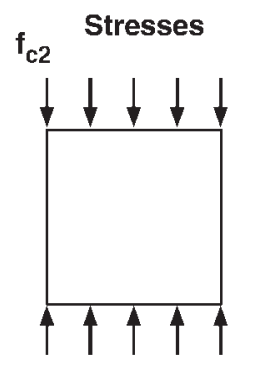

Nodal Forces
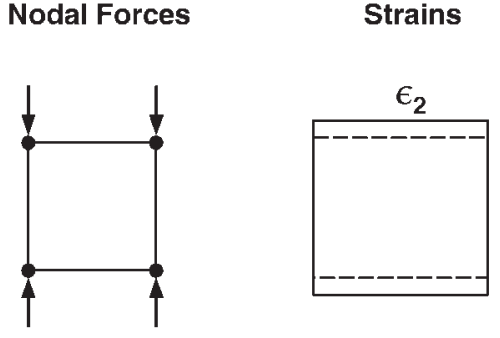

$\mathbf{f}_{\mathrm{c} 2}=\mathbf{0}$
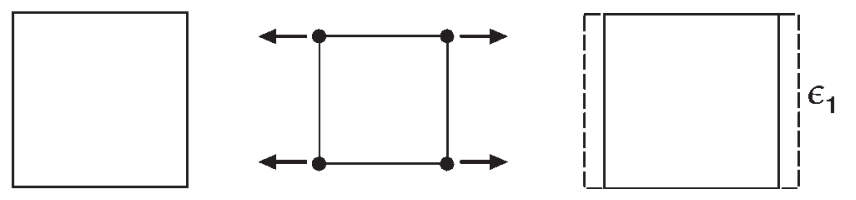

[18]

$$
\left[D_{\mathrm{c}}\right]^{\prime}=\left[\begin{array}{cccccc}
E_{\mathrm{c} 1} & 0 & 0 & 0 & 0 & 0 \\
0 & E_{\mathrm{c} 2} & 0 & 0 & 0 & 0 \\
0 & 0 & E_{\mathrm{c} 3} & 0 & 0 & 0 \\
0 & 0 & 0 & G_{\mathrm{c} 12} & 0 & 0 \\
0 & 0 & 0 & 0 & G_{\mathrm{c} 23} & 0 \\
0 & 0 & 0 & 0 & 0 & G_{\mathrm{c} 13}
\end{array}\right]
$$

where $E_{\mathrm{c} 1}, E_{\mathrm{c} 2}$, and $E_{\mathrm{c} 3}$ are the secant moduli given by

$$
\begin{aligned}
& \text { [19] } E_{\mathrm{c} 1}=\frac{f_{\mathrm{c} 1}}{\varepsilon_{1}} \\
& {[20] \quad E_{\mathrm{c} 2}=\frac{f_{\mathrm{c} 2}}{\varepsilon_{2}}} \\
& {[21] \quad E_{\mathrm{c} 3}=\frac{f_{\mathrm{c} 3}}{\varepsilon_{3}}}
\end{aligned}
$$

and the shear moduli are given by

$$
G_{\mathrm{c} 12}=\frac{E_{\mathrm{c} 1} E_{\mathrm{c} 2}}{E_{\mathrm{c} 1}+E_{\mathrm{c} 2}}
$$$$
\text { [23] } G_{\mathrm{c} 23}=\frac{E_{\mathrm{c} 2} E_{\mathrm{c} 3}}{E_{\mathrm{c} 2}+E_{\mathrm{c} 3}}
$$

$$
G_{\mathrm{c} 13}=\frac{E_{\mathrm{c} 1} E_{\mathrm{c} 3}}{E_{\mathrm{c} 1}+E_{\mathrm{c} 3}}
$$

The principal strains used in eqs. [19]-[21] are strains due to stress, not total strains. That is, any nonstress-related strains (due to prestressing, thermal expansion, etc.) and the expansion strains are first subtracted from the total strains before calculating the principal values. The prestrain approach is valid for both uncracked and cracked concrete. An iterative procedure is required for finite element analysis based on this approach.

The concept can be further explained with the example shown in Fig. 2. Consider the linear elastic biaxial element subjected to the uniaxial stress $f_{\mathrm{c} 2}$. In the traditional approach, eq. [1] would be used to determine the strains corresponding to this stress state. With the prestrain concept, no lateral expansion is included in the material stiffness matrix (see eq. [18]). The deformation response comprises an axial strain under the applied stress (with no corresponding lateral strain) and a lateral strain produced from the fictitious lateral forces (with no corresponding axial strain). The magnitude of the lateral forces is chosen to produce the lateral strain determined from eq. [14].

\section{Material modeling}

To describe the response of reinforced concrete, models are required for strength degradation due to cracking, strength enhancement due to confinement, pre- and post-peak stress-strain response in tension and compression, and concrete lateral expansion. These factors must be considered when determining the six material constants $\left(E_{1}, E_{2}, E_{3}, v_{12}, v_{21}, v_{13}\right)$ required for the orthotropic formulation described above.

The constitutive equations for multiaxial stress states are based on modifications to the concrete uniaxial stress-strain curve. The following curve, based on modifications to the work of Thorenfeldt et al. (1987) and Popovics (1973), was suggested for high strength concrete by Collins and Porasz (1989):

[25] $f_{\mathrm{c} 3}=-f_{\mathrm{p}} \frac{\varepsilon_{3}}{\varepsilon_{\mathrm{p}}} \frac{n}{n-1+\left(\varepsilon_{3} / \varepsilon_{\mathrm{p}}\right)^{n k}}$

where $n$ is given by

[26] $n=0.80+\frac{f_{\mathrm{p}}}{17}$

and $k$ equals 1 for the ascending branch and

[27] $k=0.67+\frac{f_{\mathrm{p}}}{62}$

for the descending branch (where $f_{\mathrm{c}}^{\prime}$ is in $\mathrm{MPa}$ ). Note that $f_{\mathrm{p}}$ (positive quantity) and $\varepsilon_{\mathrm{p}}$ (negative quantity) are the peak stress and the strain at peak stress, respectively.

For this curve, the strain at peak stress under uniaxial compression is estimated from

[28] $\varepsilon_{\mathrm{o}}=\frac{n}{n-1} \frac{f_{\mathrm{c}}^{\prime}}{E_{\mathrm{c}}}$

where $f_{c}^{\prime}$ is the uniaxial cylinder strength (positive quantity). The effect of the cylinder strength on the shape of this curve is 
Fig. 3. Concrete constitutive model: $(a)$ effect of $f_{\mathrm{c}}^{\prime}$ on the shape of the base curve; $(b)$ peak stress and corresponding peak strain in confined concrete; $(c)$ compressive stress-strain model for confined concrete; $(d)$ increase in Poisson's ratio near ultimate; $(e)$ strength reduction in cracked concrete; and $(f)$ tension stiffening.

(a)

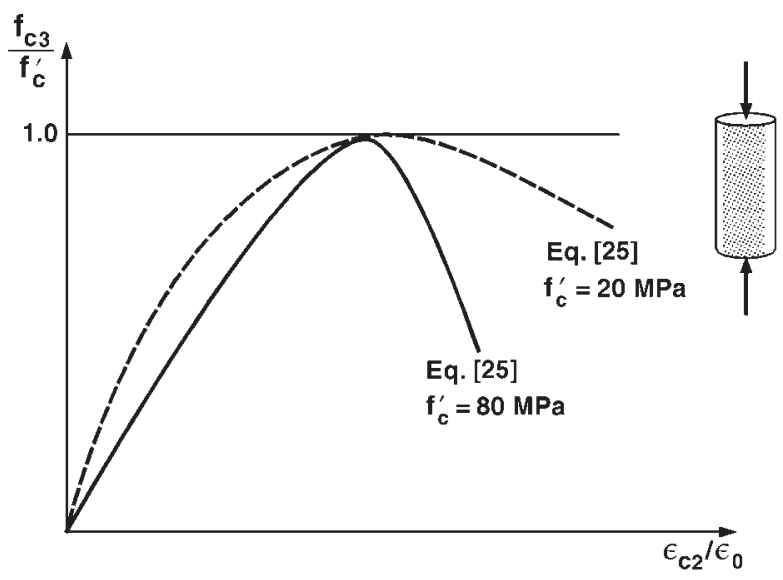

(b)

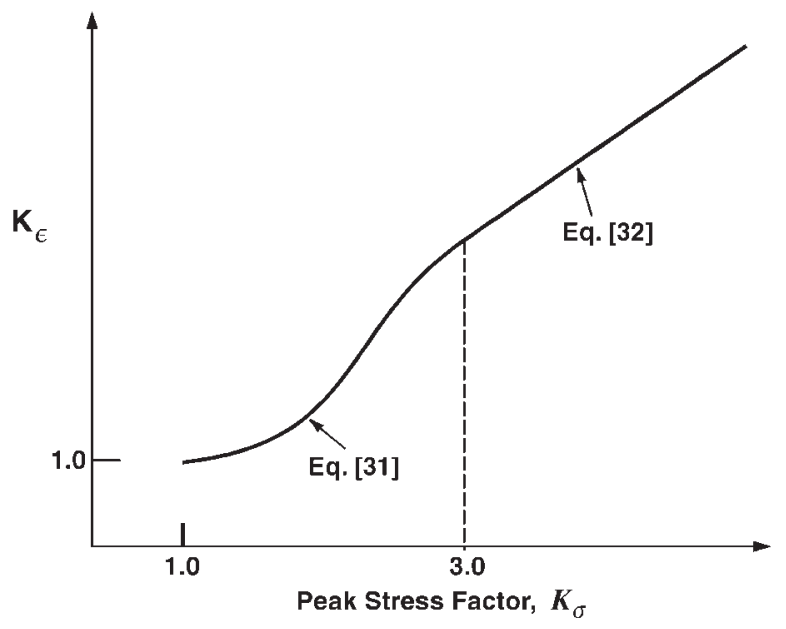

(c)

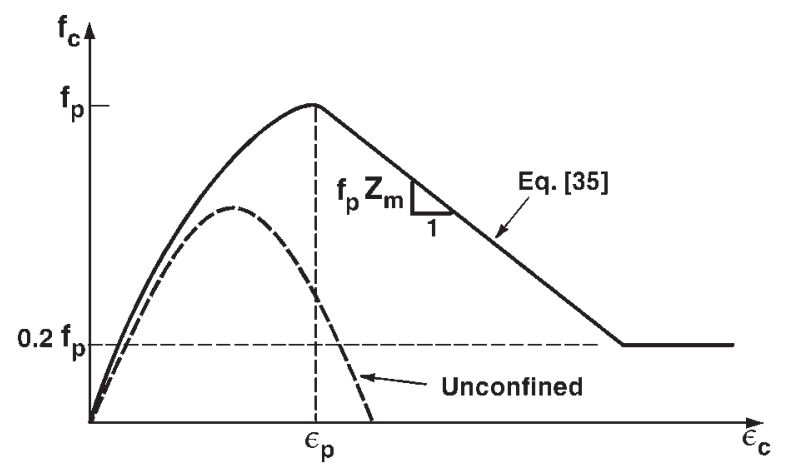

shown in Fig. $3 a$. The uniaxial stress-strain response of high strength concrete is more linear in the ascending branch, and the descending branch drops off more sharply as the concrete strength increases.

Lateral confining stresses increase the strength and the strain at peak stress of concrete cylinders. The strength enhancement is modelled by modifying the peak stress of the base curve. The failure surface of Hsieh et al. (1979) (d)

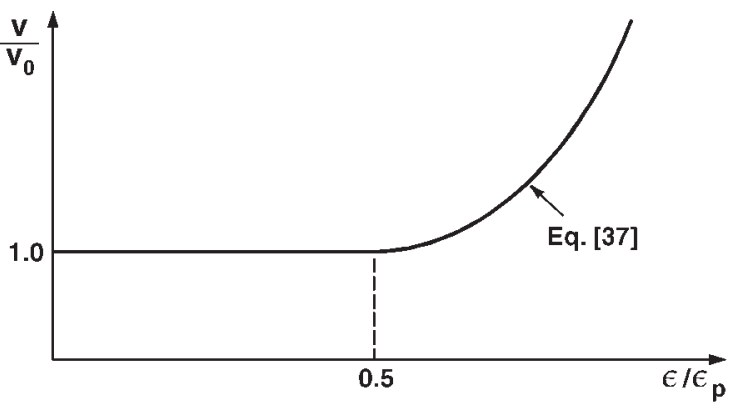

(e)

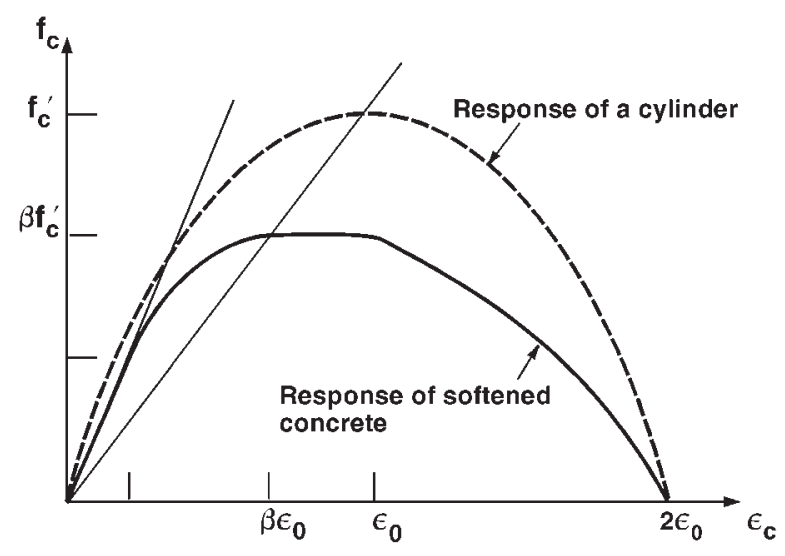

(f)

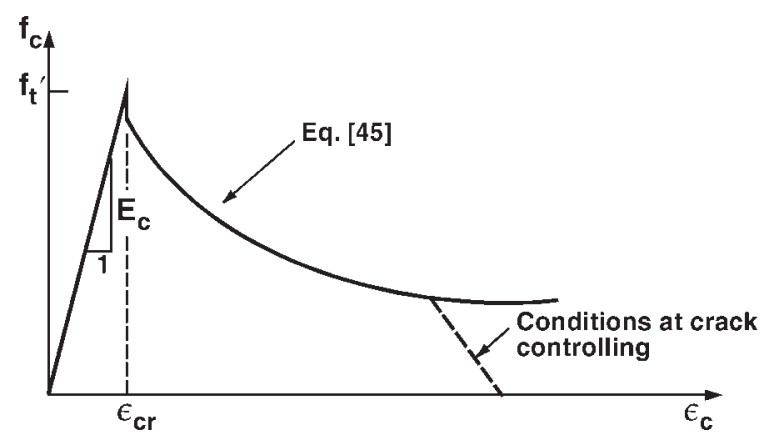

[29]

$$
\begin{aligned}
2.0108 \frac{J_{2}}{f_{c}^{\prime 2}}+0.9714 \frac{\sqrt{J_{2}}}{f_{c}^{\prime}}+9.1412 \frac{f_{\mathrm{c} 1}}{f_{c}^{\prime}}+0.2312 \frac{I_{1}}{f_{c}^{\prime}} \\
-1=0
\end{aligned}
$$

is used to find the stress required in the major compressive direction to cause failure, $f_{\mathrm{c} 3 \mathrm{f}}$, in the presence of the stresses $f_{\mathrm{c} 1}$ and $f_{\mathrm{c} 2}$. The stress $f_{\mathrm{c} 3 \mathrm{f}}$ (a negative quantity) is used as the peak stress of the base curve and a peak stress factor, $K_{\sigma}$, is defined as 


$$
K_{\sigma}=-\frac{f_{\mathrm{c} 3 \mathrm{f}}}{f_{\mathrm{c}}^{\prime}}
$$

While experimental evidence suggests the same factor can be applied to find the peak stress and the corresponding peak strain in cracked concrete, different factors must be applied to $f_{\mathrm{c}}^{\prime}$ and $\varepsilon_{\mathrm{o}}$ for confined concrete. The peak strain increases much more rapidly than the peak stress as confining pressure is increased. To relate the peak stress factor and the strain at peak stress factor, $K_{\varepsilon}$, a two-part expression is implemented (Fig. $3 b$ ). For low peak stress ratios $\left(K_{\sigma}<3\right)$, a fit to the data of Kupfer et al. (1969) is used:

$$
\text { [31] } \begin{aligned}
K_{\varepsilon}=0.2036 K_{\sigma}^{4}-2.819 K_{\sigma}^{3}+13.313 K_{\sigma}^{2}-24.42 K_{\sigma} \\
+13.718 \sqrt{K_{\sigma}}+1
\end{aligned}
$$

For higher peak stress ratios the expression of Richart et al. (1928) is adopted:

$$
\text { [32] } K_{\varepsilon}=5 K_{\sigma}-4
$$

The coordinates of the apex of the base curve become

$$
\begin{aligned}
& f_{\mathrm{p}}=K_{\sigma} f_{\mathrm{c}}^{\prime} \\
& \varepsilon_{\mathrm{p}}=\varepsilon_{\mathrm{o}}\left[K_{\sigma}\left(1-\frac{f_{\mathrm{c} 3}}{f_{\mathrm{c} 3 \mathrm{f}}}\right)+K_{\varepsilon}\left(\frac{f_{\mathrm{c} 3}}{f_{\mathrm{c} 3 \mathrm{f}}}\right)\right]
\end{aligned}
$$

The ratio $f_{\mathrm{c} 3} / f_{\mathrm{c} 3 \mathrm{f}}$ is a measure of the degree of nonlinearity. When this value is low, the strain at peak stress is close to $K_{\sigma} \varepsilon_{0}$. Nearer the ultimate strength, the strain at peak stress becomes closer to $K_{\varepsilon} \varepsilon_{0}$. The modified stress-strain curve is then used to determine all three concrete principal stresses from the corresponding principal strains.

Increased ductility is evident when concrete is confined. To simulate the descending branch (Fig. 3c) of the stress-strain curve of confined concrete, a modification was made to the modified Kent-Park model (Scott et al. 1982). The descending branch is

$$
f_{\mathrm{c} 3}=-f_{\mathrm{p}}\left[1+Z_{\mathrm{m}}\left(\varepsilon_{\mathrm{c} 3}-\varepsilon_{\mathrm{p}}\right)\right] \leq-0.2 f_{\mathrm{p}}
$$

where

$$
Z_{\mathrm{m}}=\frac{0.5}{\frac{3+0.29 f_{\mathrm{c}}^{\prime}}{145 f_{\mathrm{c}}^{\prime}-1000}\left(\frac{\varepsilon_{\mathrm{o}}}{-0.002}\right)+\left(\frac{-I_{1}+f_{\mathrm{ci}}}{170}\right)^{0.9}+\varepsilon_{\mathrm{p}}}
$$

Note that $I_{1}$ is the first stress invariant, $f_{\mathrm{ci}}$ is the current stress in the principal direction under consideration, and both $\varepsilon_{\mathrm{o}}$ and $\varepsilon_{\mathrm{p}}$ are negative quantities. This equation assumes that $f_{\mathrm{c}}^{\prime}$ is expressed in megapascals ( $\mathrm{MPa})$.

Lateral expansion increases rapidly near the peak stress (Fig. 3d). This behaviour is modelled by a fit to the uniaxial Poisson's ratio data of Kupfer et al. (1969):

$$
v_{i j}= \begin{cases}v_{0}, & 0>\varepsilon_{j}>\frac{K_{\sigma} \varepsilon_{0}}{2} \\ v_{\mathrm{o}}\left[1+1.5\left(\frac{2 \varepsilon_{j}}{K_{\sigma} \varepsilon_{0}}-1\right)^{2}\right] \leq 0.5, & \frac{K_{\sigma} \varepsilon_{\mathrm{o}}}{2}>\varepsilon_{j}\end{cases}
$$

where $v_{0}$ is the initial Poisson's ratio. This relationship implies that only three Poisson's ratios are independent, since

$$
\text { [38] } \begin{aligned}
v_{21} & =v_{31} \\
v_{12} & =v_{32} \\
v_{13} & =v_{23}
\end{aligned}
$$

For uncracked concrete in tension, the initial Poisson's ratio is used. Upon cracking in the tensile principal direction, only the expansion normal to this direction is set to zero (i.e., $v_{21}=$ $v_{31}=0$, but all other Poisson's ratios are nonzero). If the intermediate principal direction also cracks, $v_{12}$ and $v_{32}$ are equated to zero, too. All Poisson's ratios are zero if three orthogonal tensile failures occur.

In cracked concrete, large tensile strains perpendicular to the principal compressive direction reduce the concrete compressive strength. Thus, the compressive stress $f_{\mathrm{c} 3}$ is made a function of the tensile principal strain, $\varepsilon_{1}$, in addition to the compressive principal strain, $\varepsilon_{3}$. The strength reduction factor $\beta$ (Fig. 3e) for cracked concrete is given by

$$
\text { [39] } \beta=\frac{1}{1+K_{\mathrm{s}} K_{\mathrm{f}}}
$$

where

$$
\begin{aligned}
& \text { [40] } K_{\mathrm{s}}=0.35\left(\frac{-\varepsilon_{1}}{\varepsilon_{3}}-0.280\right)^{0.80} \\
& \text { [41] } K_{\mathrm{f}}=0.1825 \sqrt{f_{\mathrm{c}}^{\prime}}
\end{aligned}
$$

and $f_{\mathrm{c}}^{\prime}$ is expressed in $\mathrm{MPa}$. The $K_{\mathrm{s}}$ factor accounts for the effect of the transverse straining and $K_{\mathrm{f}}$ represents the influence of the concrete cylinder strength. High strength concrete is thought to exhibit a more pronounced compression softening effect due to the smoother fracture planes.

The peak stress and strain of the base curve are modified to account for this strength degradation effect

$\begin{aligned} & {[42] } f_{\mathrm{p}}=\beta f_{\mathrm{c}}^{\prime} \\ & \text { [43] } \varepsilon_{\mathrm{p}}=\beta \varepsilon_{\mathrm{o}}\end{aligned}$

A linear tensile stress-strain relationship is used until the concrete tensile principal stress, $f_{\mathrm{cl}}$, reaches the concrete tensile strength, $f_{\mathrm{t}}^{\prime}$, which is estimated from
[44] $f_{\mathrm{t}}^{\prime}=0.33 \sqrt{f_{\mathrm{c}}^{\prime}}$
(MPa)

Owing to the influence of bond, tensile stresses can develop in the concrete between cracks. Adding a descending branch in the post-cracked region accounts for this tension stiffening effect. The response of reinforced concrete in tension (Fig. $3 f$ ) is given by

$$
f_{\mathrm{c} 1}= \begin{cases}E_{\mathrm{c}} \varepsilon_{1}, & 0<\varepsilon_{1}<\varepsilon_{\mathrm{cr}} \\ \frac{f_{\mathrm{t}}^{\prime}}{1+\sqrt{200 \varepsilon_{1}}}, & \varepsilon_{1}>\varepsilon_{\mathrm{cr}}\end{cases}
$$

To determine the stress in the intermediate principal direction, eqs. [39] through [43] are used with the appropriate base curve if $\varepsilon_{2}$ is compressive, and eq. [44] is used if it is tensile.

The presence of average tensile stresses in the concrete implies local stress increases in the reinforcement at crack locations. Thus, local conditions must be checked to ensure that the concrete tensile stress calculated from eq. [53] can be transmitted across the crack. The average tensile stress in the concrete must not be greater than the sum of the reserve of 
Fig. 4. Reinforcement stress-strain relationship.

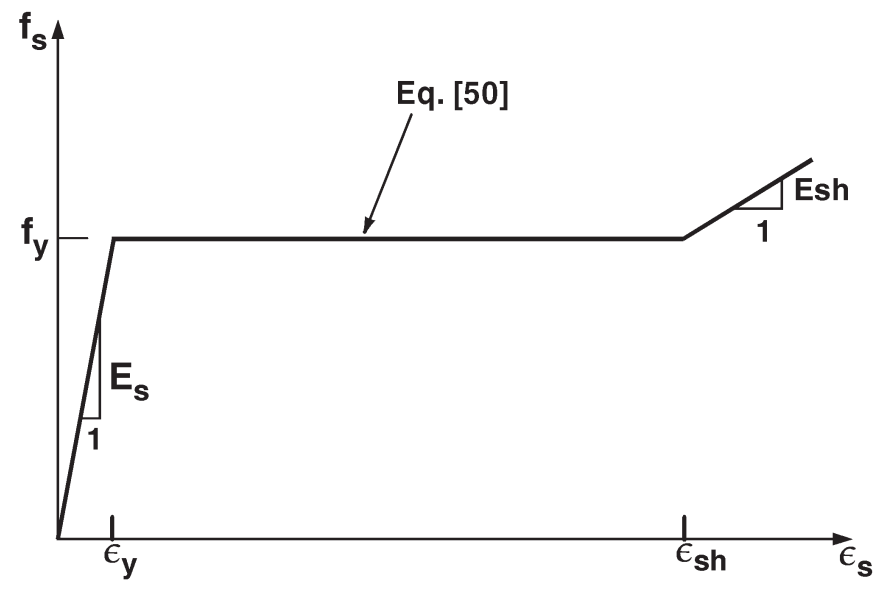

strength of each reinforcement direction taken in the perpendicular direction to a crack. If this condition is violated, then $f_{\mathrm{c} 1}$ must be reduced accordingly. This is expressed algebraically as

$$
f_{\mathrm{c} 1} \leq \sum_{i=1}^{n} \cos ^{2} \theta_{\mathrm{c} i} \rho_{i}\left(f_{\mathrm{y} i}-f_{\mathrm{s} i}\right)
$$

where $f_{\mathrm{y} i}$ is the yield stress of the reinforcement, $f_{\mathrm{s} i}$ is the average tensile stress in the reinforcement, and $\theta_{\mathrm{c} i}$ is the angle between the reinforcement and the normal to the crack surface. This check is made for the principal tensile direction and also the intermediate principal direction, if it is tensile.

Tensile stresses may also be limited if the required shear stresses cannot be supported on the crack surfaces. The local increases in the reinforcement stresses may require shear stresses on the crack surfaces for equilibrium. As the crack width increases, the ability of the concrete to transmit shear by aggregate interlock decreases. This may inhibit the local stress increases in the reinforcement and in turn limit the average concrete tensile stress. Crack slip is said to occur if the required shear stresses cannot be supported at higher crack widths. The crack width, $w$, is estimated from

\section{[47] $w=\varepsilon_{1} s$}

where $s$ is the crack spacing which must be estimated before an analysis is performed. This can be determined from the crack control characteristics of the reinforcement, or estimated from the reinforcement spacing. Vecchio and Collins (1986) suggested that in the absence of compressive stresses on the crack, the limiting shear stress (in MPa) on the crack can be estimated from

$$
v_{\mathrm{ci}}^{\max } \leq \frac{0.18 \sqrt{f_{\mathrm{c}}^{\prime}}}{0.3+\frac{24 w}{a+16}}
$$

where $a$ is the aggregate size. This equation requires units of $\mathrm{MPa}$ and $\mathrm{mm}$. The calculated shear stress on the crack surface, $v_{\mathrm{ci}}$, in the tensile principal direction is compared against $v_{\mathrm{ci}}^{\max }$. If the limiting shear stress is exceeded, then the average concrete tensile stress, $f_{\mathrm{c} 1}$, is reduced to $f_{\mathrm{c} 1}^{*}$ according to
[49] $f_{\mathrm{c} 1}^{*}=\frac{v_{\mathrm{ci}}^{\max }}{v_{\mathrm{ci}}} f_{\mathrm{c} 1}$

Reinforcement stresses are related to strains using an elasticplastic formulation that includes strain hardening behaviour. The constitutive relationship, shown in Fig. 4, is expressed as

$$
f_{\mathrm{si}}= \begin{cases}E_{\mathrm{s}} \varepsilon_{\mathrm{si}}, & 0<\varepsilon_{\mathrm{si}} \leq \varepsilon_{\mathrm{y}} \\ f_{\mathrm{y}}, & \varepsilon_{\mathrm{y}}<\varepsilon_{\mathrm{si}} \leq \varepsilon_{\mathrm{sh}} \\ f_{\mathrm{y}}+E_{\mathrm{sh}}\left(\varepsilon_{\mathrm{si}}-\varepsilon_{\mathrm{sh}}\right) \leq f_{\mathrm{u}}, & \varepsilon_{\mathrm{si}}>\varepsilon_{\mathrm{sh}}\end{cases}
$$

where $E_{\mathrm{s}}$ is the modulus of elasticity, $E_{\mathrm{sh}}$ is the modulus of strain hardening, $\varepsilon_{\mathrm{sh}}$ is the strain at the onset of strain hardening, $f_{\mathrm{y}}$ is the yield strength, and $f_{\mathrm{u}}$ is the ultimate strength of the reinforcement. Perfect bond is assumed between the concrete and steel.

The algorithm used to solve for the stresses and strains in a reinforced concrete solid under externally applied loads involves the following steps. An analysis begins by assuming linear elastic isotropic material properties. Element stiffness matrices are calculated and the global stiffness assembled. The load vector, which includes prestrain and expansion effects, is then formed. Nodal displacements are determined, from which one strain tensor is calculated for each element. Principal strains and corresponding directions are found. Evaluation of the concrete and steel stresses using the constitutive models permits determination of secant moduli and in turn new material stiffness matrices. Average secant moduli are calculated and if they have converged to the specified limit, then the load stage is complete. Convergence is measured by the root mean square, taken over the three principal directions for all elements, of the ratio of the newly calculated secant stiffness factor to the previous secant stiffness factor. Typically, the limit for this value is taken as 1.0001. If the load stage is not complete, the newly calculated material stiffness values are used to perform another linear elastic analysis. Normally, satisfactory convergence is achieved within 10-25 iterations. A flowchart of this procedure is shown in Fig. 5.

\section{Sample analysis}

Lefas et al. (1990) tested several walls under conditions of constant axial load and monotonically increasing lateral load. An analysis of one of these walls provides an opportunity to examine the effects of accounting for confinement and lateral expansion in a compression field based analysis. Shear wall SW16 (Fig. 6) had a height-to-width ratio of 1.0, a rectangular cross section, and heavily reinforced, thickened regions at the top and bottom of the wall to facilitate load transfer. The wall was reinforced vertically with two layers of $8 \mathrm{~mm}$ diameter bars spaced at $60 \mathrm{~mm}$ and horizontally with two layers of $6.25 \mathrm{~mm}$ diameter bars spaced at $80 \mathrm{~mm}$. Closed ties were included near the edges of the wall, creating $140 \mathrm{~mm}$ wide concealed columns.

The wall showed a ductile response and was able to resist a higher than expected load. This was attributed to the confinement of the concrete in the concealed column at the base of the wall. Triaxial compressive stress conditions were reported for this region.

The concrete properties input to the program were a cylinder strength of 44.0 MPa, an initial secant modulus of 33150 
Fig. 5. SPARCS solution algorithm.

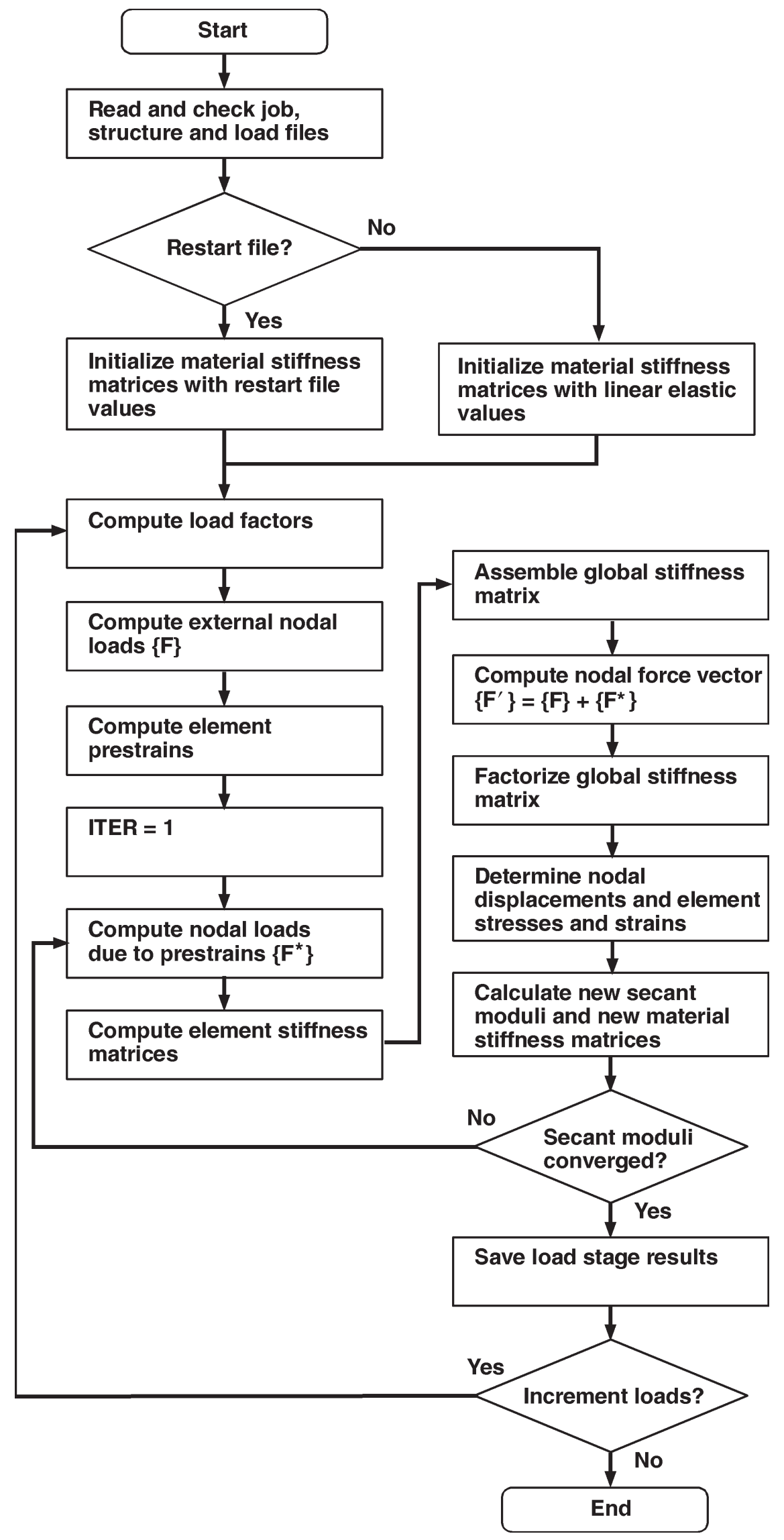


Fig. 6. Details of shear wall SW16.

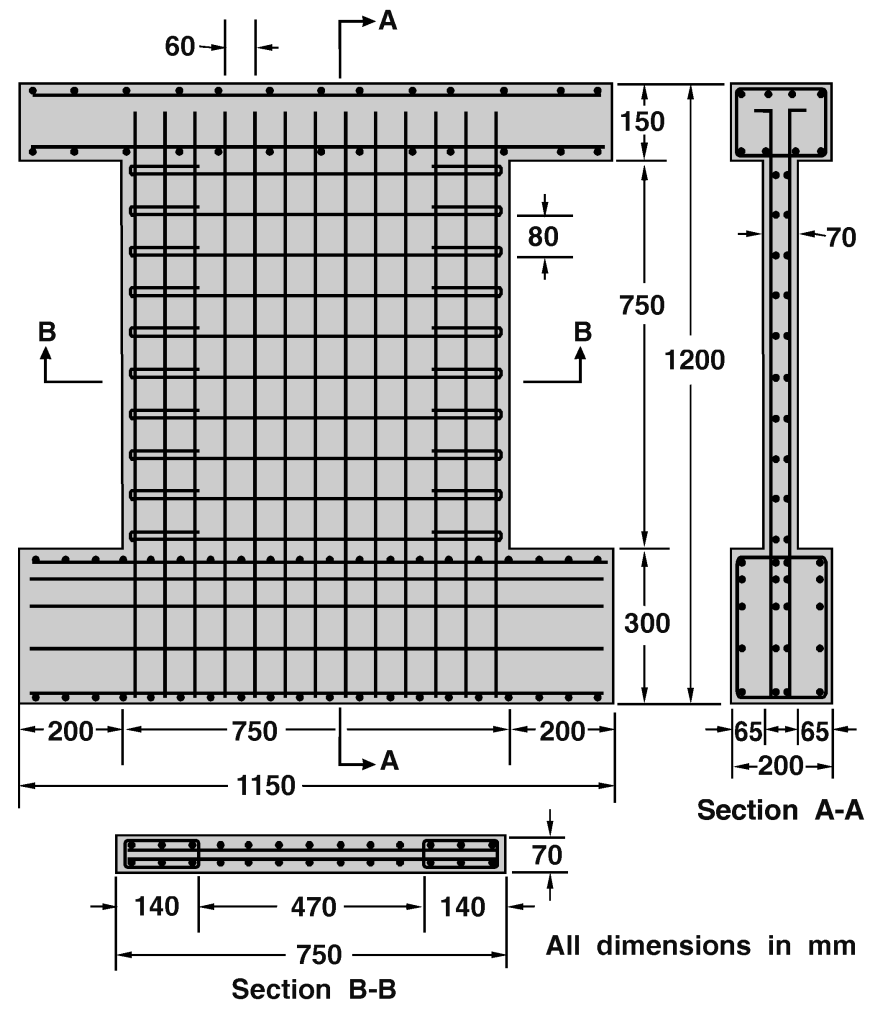

$\mathrm{MPa}$, and an initial Poisson's ratio of 0.15 . The reinforcement had yield strengths of 470, 520, and $420 \mathrm{MPa}$ for the 8, 6.25, and $4 \mathrm{~mm}$ bars, respectively. The modulus of elasticity of the reinforcement was $210000 \mathrm{MPa}$ and strain hardening was assumed to begin at a strain of $2.5 \times 10^{-3}$, with a strain hardening modulus of $10000 \mathrm{MPa}$.

A mesh of 310 brick elements was used to model the spreader beams and wall (Fig. 7a). One element was used across the width of a concealed column. Loads were applied to the top spreader beam as equivalent nodal loads. The nodes along the lower edge of the base were fixed. A smeared steel model was used to account for the presence of the reinforcement. Two material zones were defined for the wall and one region each for the spreader beams (Fig. 7b).

The vertical load of $460 \mathrm{kN}$ was applied to the top spreader beam and the horizontal load was increased monotonically until failure. The ultimate horizontal load of $350 \mathrm{kN}$ obtained from the SPARCS analysis compared well with the experimental value of $355 \mathrm{kN}$. The analytical response involved flexural-shear cracking, followed by yielding of the vertical reinforcement on the tension side, and ultimately crushing of the concrete near the base on the compression side. This was in agreement with the experimentally observed response. The load-deformation response was also well represented. The deflection at the centreline of the top of the wall is plotted against the applied horizontal load in Fig. $8 a$. The shape of the load-deformation curve matches the measured response, but the deflections are somewhat underestimated near ultimate.

Of particular interest is the calculated stress condition near the base on the compression side of the wall. The distribution of compressive stresses across the base of the wall at the ultimate load is shown in Fig. $8 b$. The analytical principal com-
Fig 7. Finite element model of SW16: (a) SPARCS finite element mesh and $(b)$ reinforced concrete element type zones.

(a)
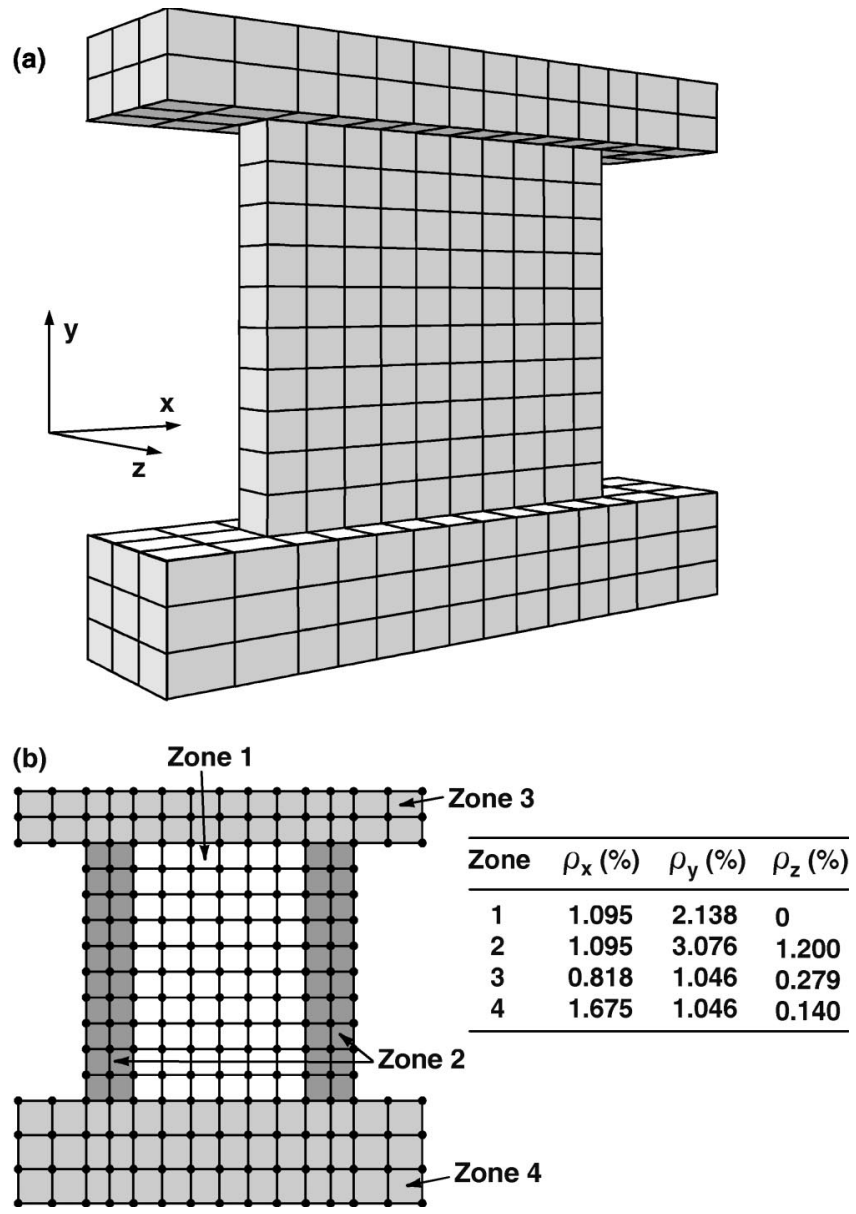

pressive stress on the compression side of the wall was equal to $1.52 f_{\mathrm{c}}^{\prime}$. At this location, triaxial compressive stress conditions resulted because of the passive confinement provided by the hoop steel and the thickened region at the base of the wall. The analytical principal compressive stresses in the concrete were $f_{\mathrm{c} 1}=-1.39 \mathrm{MPa}, f_{\mathrm{c} 2}=-5.10 \mathrm{MPa}$, and $f_{\mathrm{c} 3}=-67.0 \mathrm{MPa}$. The reinforcement in the out-of-plane direction was approaching yield. The principal compressive strain of $-5.80 \times 10^{-3}$ was well into the post-peak regime.

An additional analysis was run without consideration of expansion and strength increase effects. That is, $f_{\mathrm{p}}$ was held constant at $f_{\mathrm{c}}^{\prime}$ and the poisson's ratios were held constant at 0.15 . The maximum horizontal applied load was reduced to $285 \mathrm{kN}$ (see Fig. 8a). There was a substantial reduction in the strength and in the ductility near ultimate, but little influence at low to intermediate load levels. This analysis failed by crushing of the concrete at the base on the compression side at a stress equal to the cylinder strength. Therefore, the confinement model proved crucial in providing a realistic response for this wall.

The SPARCS program has also been able to successfully capture the response of a variety of reinforced concrete elements, including shear panels, beam elements, and shell elements (Selby and Vecchio 1993; Vecchio and Selby 1991). The program has also been used to conduct local nonlinear analyses 
Fig. 8. Finite element analysis results for SW16: (a) load-deformation response of SW16 and $(b)$ predicted stress distributions along base of wall at ultimate.

(a)

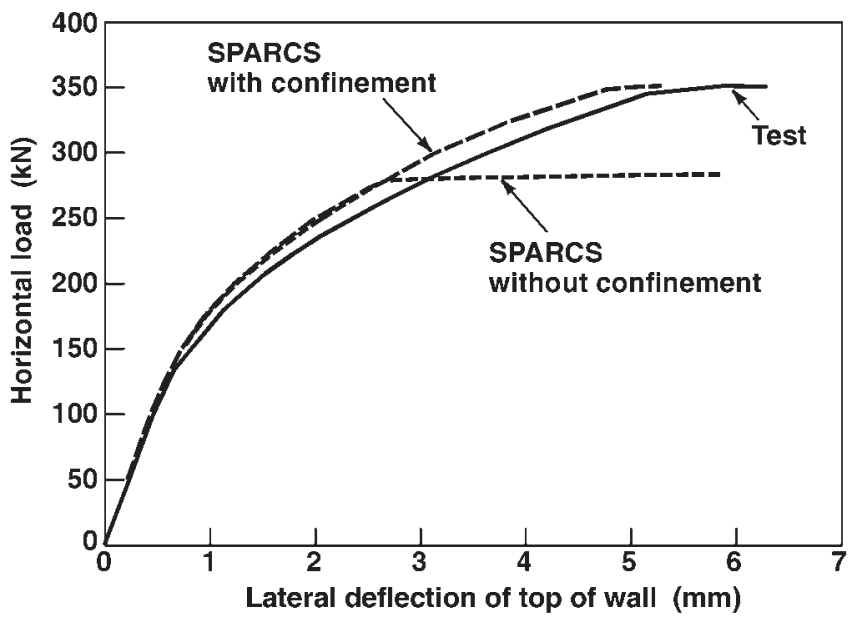

(b)

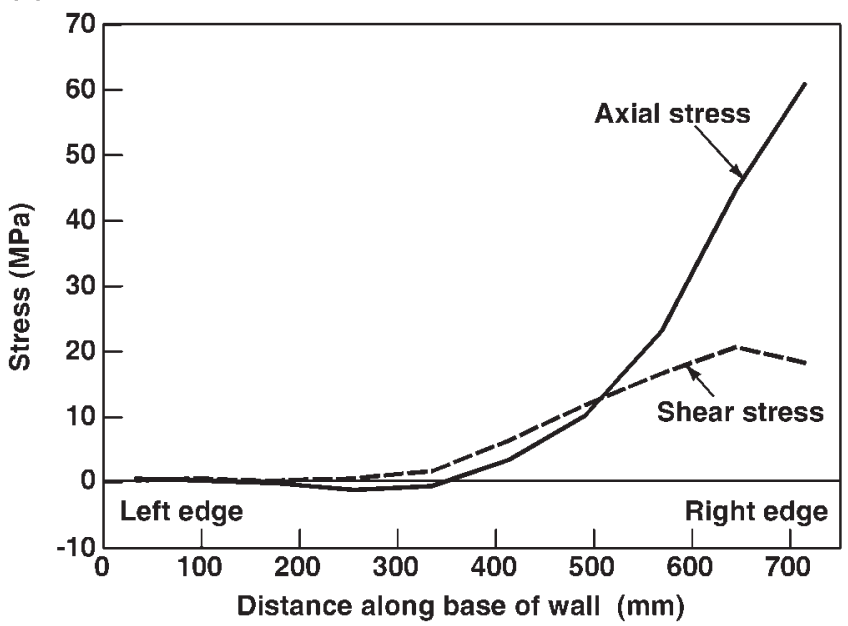

of concrete offshore platforms to investigate reasons for structural failure (Collins et al. 1997), and to confirm the design of critical components (Selby et al. 1996). Work is progressing with regards to application to confined columns and to cyclic and non-proportional loading.

\section{Conclusion}

A constitutive model was presented for predicting the response of reinforced concrete solids subject to short-term monotonic loading. The model was built into a finite element program, thereby permitting three-dimensional nonlinear analyses of complex reinforced concrete structures.

A confined concrete model was developed to be compatible with the secant stiffness based modified compression field theory, cracked concrete formulation. The simple constitutive equations proposed for confined concrete were capable of predicting concrete strength enhancement, dilatancy and postpeak compressive response under triaxial compressive stresses.

The orthotropic nonlinear elastic secant algorithm was a successful framework for the confined concrete model. The theory accounted for anisotropic behaviour, but did not require enforcement of the unrealistic symmetry conditions. The prestrain approach handled the asymmetry of the material stiffness matrices in a numerically stable manner, with only a modest increase in storage and solution time requirements.

The formulation presented herein is simple and flexible. Any set of realistic constitutive relationships can easily be incorporated into the program. Further work needs to be directed at improving the preliminary confined concrete stress-strain models. Also, there is currently a lack of adequate experimental data from which to calibrate three-dimensional constitutive relationships for cracked reinforced concrete. The influence of the intermediate principal strain on the compression softening and tension stiffening effects could be quantified once suitable data are obtained.

The analysis of a shear wall demonstrated the significance of the confinement model in providing a good estimate of strength. The concealed column at the edge of the wall was subjected to triaxial stress conditions. Ignoring confinement effects resulted in a significant decrease in wall capacity and ductility.

\section{References}

Adeghe, L.N. 1986. A finite element model for studying reinforced concrete detailing problems. Ph.D. thesis, Department of Civil Engineering, University of Toronto, Toronto, Ont.

Collins, M.P., and Porasz, A. 1989. Shear design for high-strength concrete. Comité Euro-International du Béton, Bulletin d'Information No. 193, pp. 77-83.

Collins, M.P., Vecchio, F.J., Selby, R.G., and Gupta, P.R. 1997. Investigating the failure of an offshore structure. Concrete International, 19(8)

Hsieh, S.S., Ting, E.C., and Chen, W.F. 1979. An elastic-fracture model for concrete. Proceedings of the 3rd Engineering Mechanics Division Special Conference, American Society of Civil Engineers, Austin, Tex., pp. 437-440.

$\mathrm{Hu}$, H.T., and Schnobrich, W.C. 1990. Nonlinear analysis of cracked reinforced concrete. American Concrete Institute Structural Journal, 87(2): 199-207.

Kupfer, H., Hilsdorf, K.H., and Rüsch, H. 1969. Behaviour of concrete under biaxial stress. Journal of the American Concrete Institute, 66(8): 656-666.

Lefas, I.D., Kotsovos, M.D., and Ambraseys, N.N. 1990. Behaviour of reinforced concrete structural walls: strength, deformation characteristics and failure mechanism. American Concrete Institute Structural Journal, 87(1): 23-31.

Popovics, S. 1973. A numerical approach to the complete stress-strain curve of concrete. Cement and Concrete Research, 3(5): 553-599.

Richart, F.E., Brandzaeg, A., and Brown, R.L. 1928. A study of the failure of concrete under combined compressive stresses. University of Illinois Engineering Experimental Station, Urbana, Ill., Bulletin No. 185.

Scott, B.D., Park, R., and Priestley, M.J.N. 1982. Stress-strain behaviour of concrete confined by overlapping hoops at low and high strain rates. Journal of the American Concrete Institute, 79(1): 13-27.

Selby, R.G., and Vecchio, F.J. 1993. Three dimensional constitutive relations for reinforced concrete. Department of Civil Engineering, University of Toronto, Toronto, Ont., Publication No. 93-02.

Selby, R.G., Vecchio, F.J., and Collins, M.P. 1996. Analysis of reinforced concrete sections subjected to shear and high axial compression. American Concrete Institute Structural Journal, 93(3): 306-315.

Stevens, N.J. 1987. Analytical modelling of reinforced concrete subjected to monotonic and reversed loadings. Ph.D. thesis, Department of Civil Engineering, University of Toronto, Toronto, Ont. 
Thorenfeldt, E., Tomaszewicz, A., and Jensen, J.J. 1987. Mechanical properties of high strength concrete and application in design. Proceedings of the Symposium on Utilization of High Strength Concrete, Tapir, Trondheim, Norway, pp. 149-159.

Vecchio, F.J. 1989. Nonlinear finite element analysis of reinforced concrete membranes. American Concrete Institute Structural Journal, 86(1): 26-35.

Vecchio, F.J. 1992. Finite element modelling of concrete expansion and confinement. ASCE Journal of Structural Engineering, 118(9): 2390-2406.

Vecchio, F.J., and Collins, M.P. 1982. The response of reinforced concrete to in-plane shear and normal stresses. Department of Civil Engineering, University of Toronto, Toronto, Ont., Publication No. 82-03.

Vecchio, F.J., and Collins, M.P. 1986. The modified compression field theory for reinforced concrete elements subjected to shear. Journal of the American Concrete Institute, 83(2): 219-231.

Vecchio, F.J., and Selby, R.G. 1991. Toward compression field analysis of reinforced concrete solids. ASCE Journal of Structural Engineering, 117(6): 1740-1758.

\section{List of symbols}

a aggregate size

$[B]$ element strain displacement matrix

$[D]$ composite material stiffness matrix in global axes

$\left[D_{\mathrm{c}}\right]$ concrete material stiffness matrix in global axes

$\left[D_{\mathrm{c}}\right]^{\prime}$ concrete material stiffness matrix in principal directions

$\left[D_{\mathrm{s}}\right]_{i}$ material stiffness in global axes of reinforcement component $i$

$E_{\mathrm{c}}$ modulus of elasticity of concrete (initial tangent modulus)

$E_{\mathrm{c} 1}$ concrete secant modulus in tensile principal strain direction

$E_{\mathrm{c} 2} \quad$ concrete secant modulus in intermediate principal strain direction

$E_{\mathrm{c} 3} \quad$ concrete secant modulus in compressive principal strain direction

$E_{\mathrm{s}} \quad$ Young's modulus of reinforcement

$E_{\mathrm{sh}} \quad$ modulus of strain hardening of reinforcement

$f_{\mathrm{c}}^{\prime} \quad$ compressive strength of concrete cylinder (positive quantity)

$f_{\mathrm{c} 1} \quad$ tensile principal stress in concrete

$f_{\mathrm{c} 2} \quad$ intermediate principal stress in concrete

$f_{\mathrm{c} 3} \quad$ compressive principal stress in concrete

$f_{\mathrm{c} 3 \mathrm{f}}$ required $f_{\mathrm{c} 3}$ to cause failure in presence of $f_{\mathrm{c} 1}$ and $f_{\mathrm{c} 2}$

$f_{\mathrm{p}} \quad$ peak stress (positive quantity)

$f_{\mathrm{s} i} \quad$ average stress in $i$-direction reinforcement

$f_{\mathrm{u} i} \quad$ ultimate stress of $i$-direction reinforcement

$f_{\mathrm{y} i} \quad$ yield stress of $i$-direction reinforcement

$\{F\} \quad$ structure nodal force matrix

$\left\{F^{*}\right\} \quad$ equivalent nodal loads due to prestrains

$\{f\}$ element stress matrix (tension positive)
$G_{\mathrm{c} 12}$ secant shear modulus of concrete relative to 1- and 2axis

$G_{\mathrm{c} 23}$ secant shear modulus of concrete relative to 2- and 3axis

$G_{\mathrm{c} 13}$ secant shear modulus of concrete relative to 1- and 3axis

$I_{1} \quad$ first invariant of stress tensor

$J_{2}$ second invariant of deviatoric stress tensor

$K_{\varepsilon} \quad$ strain at peak stress factor (positive quantity)

$K_{\sigma} \quad$ peak stress factor (positive quantity)

$[K] \quad$ structure stiffness matrix

$[k]$ element stiffness matrix

$\left[k_{\mathrm{c}}\right]$ element stiffness matrix evaluated for concrete component

$\left[k_{\mathrm{s}}\right]_{i} \quad$ element stiffness evaluated for $i$-direction reinforcement

$\{r\} \quad$ structure nodal displacement matrix

$\left\{r_{\mathrm{c}}\right\} \quad$ free nodal displacements due to concrete prestrains

$\left\{r_{\mathrm{s}}\right\} \quad$ free nodal displacements due to steel prestrains

$s \quad$ crack spacing

$[T]$ transformation matrix

$v_{\mathrm{ci}}$ maximum allowable shear stress on crack surface

$v_{\mathrm{ci}}^{\max } \quad$ shear stress on crack surface

$w \quad$ crack width

$Z_{\mathrm{m}} \quad$ slope factor for post-peak compressive curve

$\beta \quad$ strength reduction factor

$\varepsilon_{\mathrm{cr}} \quad$ strain in concrete at cracking

$\varepsilon_{1}^{0} \quad$ concrete expansion strain in 1-direction

$\varepsilon_{2}^{0} \quad$ concrete expansion strain in 2-direction

$\varepsilon_{3}^{0} \quad$ concrete expansion strain in 3-direction

$\varepsilon_{\mathrm{o}} \quad$ strain in concrete cylinder at peak stress $f_{\mathrm{c}}^{\prime}$ (negative quantity)

$\varepsilon_{\mathrm{p}} \quad$ strain at peak stress (negative quantity)

$\varepsilon_{\mathrm{s}}^{0} \quad$ smeared reinforcement prestrains relative to global axes

$\varepsilon_{\mathrm{sh}} \quad$ strain at onset of strain hardening of reinforcement

$\varepsilon_{\mathrm{s} i} \quad$ strain in $i$-direction reinforcement

$\varepsilon_{\mathrm{y}} \quad$ yield strain of reinforcement

$\varepsilon_{1} \quad$ tensile principal strain

$\varepsilon_{1}^{\text {cr }} \quad$ tensile principal strain at a crack

$\varepsilon_{2} \quad$ intermediate principal strain

$\varepsilon_{3} \quad$ compressive principal strain

$\{\varepsilon\} \quad$ element strain matrix (tension positive)

$\left\{\varepsilon_{\mathrm{c}}^{0}\right\} \quad$ concrete prestrains relative to global axes

$\left\{\varepsilon_{\mathrm{cp}}^{\mathrm{o}}\right\} \quad$ expansion strains in principal directions

$\left\{\varepsilon_{\mathrm{s}}^{\mathrm{o}}\right\} \quad$ smeared reinforcement prestrains relative to global axes

$\rho_{i} \quad$ smeared steel reinforcement ratio in $i$-direction

$v_{i j} \quad$ component of strain in $i$-direction due to a stress in the j-direction

$v_{0} \quad$ initial Poisson's ratio

$\theta_{c i} \quad$ angle between $i$-direction steel and normal to crack surface 